Society of Photo-Optical Instrumentation Engineers (SPIE)

Copyright (2002) Society of Photo-Optical Instrumentation Engineers.

This paper will be published in the Proceedings of SPIE Annual Meeting 2002 and is made available as an electronic reprint (preprint) with permission of SPIE. One print or electronic copy may be made for personal use only. Systematic or multiple reproductions, distribution to multiple locations via electronic or other means, duplication of any material in this paper for a fee or for commercial purposes, or modifications of the content of the paper are prohibited. 


\title{
Progress in the Fabrication of High-Aspect-Ratio Zone Plates by Soft X-ray Lithography
}

\author{
Ralu Divan ${ }^{* a}$, Derrick C. Mancini ${ }^{\text {a }}$, Nicolaie Moldovan ${ }^{\text {a }}$, Barry Lai ${ }^{\text {a }}$, Lahsen Assoufid ${ }^{\text {a }}$, \\ Quinn Leonard ${ }^{\mathrm{b}}$, and Franco Cerrina ${ }^{\mathrm{b}}$ \\ advanced Photon Source, Argonne National Laboratory \\ ${ }^{\mathrm{b}}$ Center for NanoTechnology, University of Wisconsin-Madison
}

\begin{abstract}
Fabrication of Fresnel zone plates for the hard x-ray spectral region combines the challenge of high lateral resolution $(\sim 100 \mathrm{~nm})$ with a large thickness requirement for the phase-shifting material $(0.5-3 \mu \mathrm{m})$. For achieving a high resolution, the initial mask was fabricated by e-beam lithography and gold electroforming. To prevent the collapse of the structures between the developing and electroforming processes, drying was completely eliminated.

Fabrication errors, such as nonuniform gold electroplating and collapse of structures, were systematically analyzed and largely eliminated. We optimized the exposure and developing processes for $950 \mathrm{k}$ and $2200 \mathrm{k}$ polymethylmethacrylate of different thicknesses and various adhesion promoters. We discuss the effects of these fabrication steps on the zone plate's resolution and aspect ratio. Fresnel zone plates with $110 \mathrm{~nm}$ outermost zone width, $150 \mu \mathrm{m}$ diameter, and $1.3 \mu \mathrm{m}$ gold thickness were fabricated. Preliminary evaluation of the FZPs was done by scanning electron microscopy and atomic force microscopy. The FZP focusing performance was characterized at the Advanced Photon Source at Argonne National Laboratory.
\end{abstract}

Keywords: Fresnel zone plate, high aspect ratio, hard x-rays, soft x-ray lithography

\section{INTRODUCTION}

Among many x-ray microfocusing optics developed so far, Fresnel zone plates (FZP) have been demonstrated as one of the most promising microfocusing optics in both the hard $\mathrm{x}$-ray ${ }^{1}$ and the soft $\mathrm{x}$-ray spectral regions. ${ }^{2-4}$ While the initial developments were driven by the fabrication of soft x-ray microscopes, ${ }^{5}$ optimized diffractive lenses are at present also required for many other applications using various regions of the $\mathrm{x}$-ray spectrum. These applications include microanalysis, microspectroscopy, and microdiffraction. A circular FZP is a diffraction grating consisting of concentric zones in which the period decreases with radius. Different diffraction orders yield different focus. Fresnel zone plates focus X-rays into a diffraction-limited spot with a diameter of about 1.2 times the width of the outermost zone. Spot sizes in the range of tens of nanometers for soft $\mathrm{x}$-rays ${ }^{6-9}$ and of about $100 \mathrm{~nm}$ for hard $\mathrm{x}$-rays ${ }^{10-12}$ have been achieved. The diffraction efficiency of a zone plate, i.e., the fraction of the incoming radiation diffracted into a focal spot of certain order, depends on the shape of the zone structure and on the optical constant of the zone plate material. Ideally, this material should produce a strong phase shift, to avoid high aspect ratios of the outermost structures, coupled with low absorption. FZP have been fabricated by electroplating gold or nickel into polymer molds. ${ }^{10-12}$ Semiconductors are also commonly used as they can be structured with high aspect ratios by plasma etching. ${ }^{13}$

There are two main difficulties in the fabrication process of a FZP for the hard x-ray spectral region. First, the pattern generation has to provide high resolution and high placement accuracy for a large number of curved lines with continuously varying linewidth. Second, the structures have to be transferred into the phase-shifting material with high aspect ratios and controlled thickness.

\footnotetext{
* divan@aps.anl.gov; phone 1630252 0146; fax 1630252 0161; http://aps.anl.gov; Advanced Photon Source, Argonne National Laboratory, 9700 S Cass Ave., Argonne, IL 60439
} 
For the energy region from 8 to $20 \mathrm{keV}$, this translates into a range of gold phase-shifter thickness from 1.6 to $3.5 \mu \mathrm{m}$. Using nickel as the phase-shifting material would require a thickness from 3.5 to $7.0 \mu \mathrm{m}$ for the same energy region. ${ }^{14}$

In order to fabricate FZPs with adequate thickness for hard x-ray applications, stepwise thickness-increasing techniques have been developed and reported. ${ }^{10}$ The initial FZPs were produced by low-aspect-ratio electron-beam lithography and gold electroforming. Three successive copying processes done by soft $\mathrm{x}$-ray lithography and electroforming produced FZPs with adequate thickness. The x-ray lithography steps are able to preserve sub-100 $\mathrm{nm}$ resolution while increasing the aspect ratio, due to the large depth of focus and low x-ray absorption in the resist. The high aspect ratio in the replication process can be obtained by soft x-ray exposure followed by wet development, ${ }^{15}$ or a wet-silylated and dry development resist. ${ }^{16}$ Collapse of the developed polymethyl methacrylate (PMMA) rings under the superficial tension forces during drying or wetting the sample are known to be a major cause of failure. Thus, a wet process to exclude the drying procedure between the initial resist development and the final Au electroplating was developed. ${ }^{17}$ Thus, the sample does not leave the liquid environment until the electroforming is completed.

The aim of this work was to optimize the process for increasing the aspect ratio and the resolution for hard x-ray zone plates fabricated in the final replication step. Fabrication errors, such as collapse of structures and nonuniform gold electroplating, were systematically analyzed and largely eliminated. FZP with $110 \mathrm{~nm}$ outermost zone width, $150 \mu \mathrm{m}$ diameter, and $1.3 \mu \mathrm{m}$ gold thickness were fabricated. The FZP focusing performance was characterized at the Advanced Photon Source (APS), Argonne National Laboratory.

\section{FABRICATION}

The 3-step replication process for FZP fabrication using x-ray proximity printing and gold electroforming is illustrated in Fig. 1.

Fig. 1: Basic process flow chart for FZP replication.

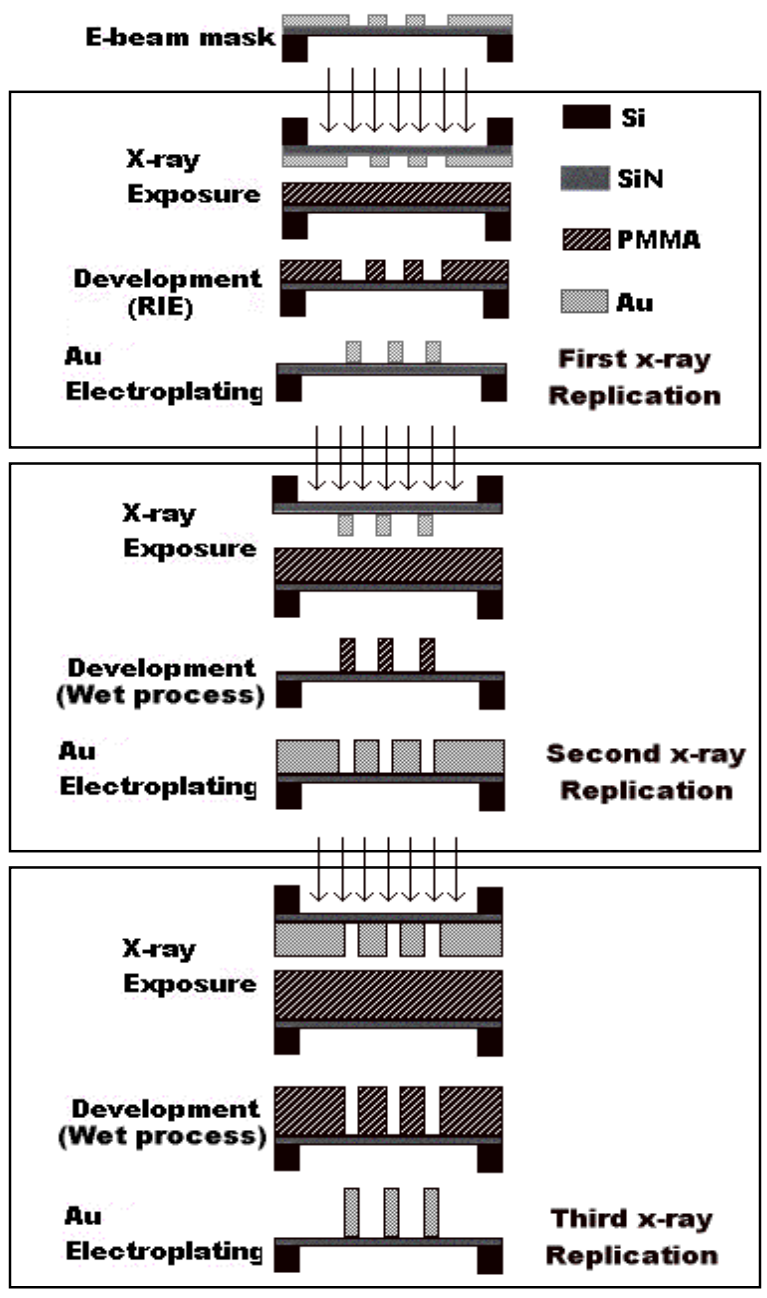


For the third step, the zone-plate carrier, a $\mathrm{Si}_{3} \mathrm{~N}_{4}$ membrane of $5 \times 5 \mathrm{~mm}^{2}$ formed on a $\mathrm{Si}$ wafer, was coated with a Ti/Au or a $\mathrm{Cr} / \mathrm{Au}$ plating base and PMMA resist and exposed thorough the x-ray mask. The x-ray lithography was carried out on the ES-1 beam line of the storage ring Aladdin ${ }^{18}$ operated at $800 \mathrm{MeV}$. The beam line, equipped with two $13 \mu \mathrm{m} \mathrm{Be}$ filters, provides $x$-ray radiation in the $\lambda \sim 0.6-1 \mathrm{~nm}$ region, with the maximum intensity at $0.73 \mathrm{~nm}$. The mask-wafer gap was set at $5 \mu \mathrm{m}$ using calibrated spacers. The exposures were performed in vacuum. The structures were developed in a methyl-isobutyl ketone (MIBK) : isopropanol (IPA) mixture. Patterns were transferred into gold by electroplating. Although the mask used for replicating the FZP has the outermost zone width of $100 \mathrm{~nm}$, the first replicas obtained reached only $150 \mathrm{~nm}$. Several possible causes were identified, and most of them were eliminated.

\subsection{Resist Processing}

PMMA 950k in anisole (methoxybenzene) with different dilutions 5.5\%, 8\%, 11\% and 2200k 6\% (MicroChem Corp.) were used for x-ray exposure. The dose required to achieve the correct resist exposure depends on the PMMAdeveloping system performance. This is a function of the PMMA composition and thickness, developer chemistry, and developing parameters.

We have investigated the influences of the absorbed dose (bulk exposure), thermal treatment temperature, development temperature $\left(20^{\circ}\right.$ and $\left.25^{\circ} \mathrm{C}\right)$, developer (MIBK: IPA and G-G system $\left.{ }^{19}\right)$ and the dilution $(1: 2$ and $1: 3$ for MIBK:IPA mixture). The PMMA was annealed at $180^{\circ}$ or $150^{\circ} \mathrm{C}$, with subsequent slow cooling for $3 \mathrm{~h}$ to reduce the residual stress in the film. The resist thickness was measured using a Filmetrics Inc. F-40 spectroscopic reflectometry system, and a KLA-Tencor alpha-step 500 profilometer. Figures 2-3 show the development rate as a function of the dose for the PMMA 950k A11 $(2.3 \mu \mathrm{m})$ and PMMA 2200k A6 $(1.4 \mu \mathrm{m})$ resists exposed with x-rays.

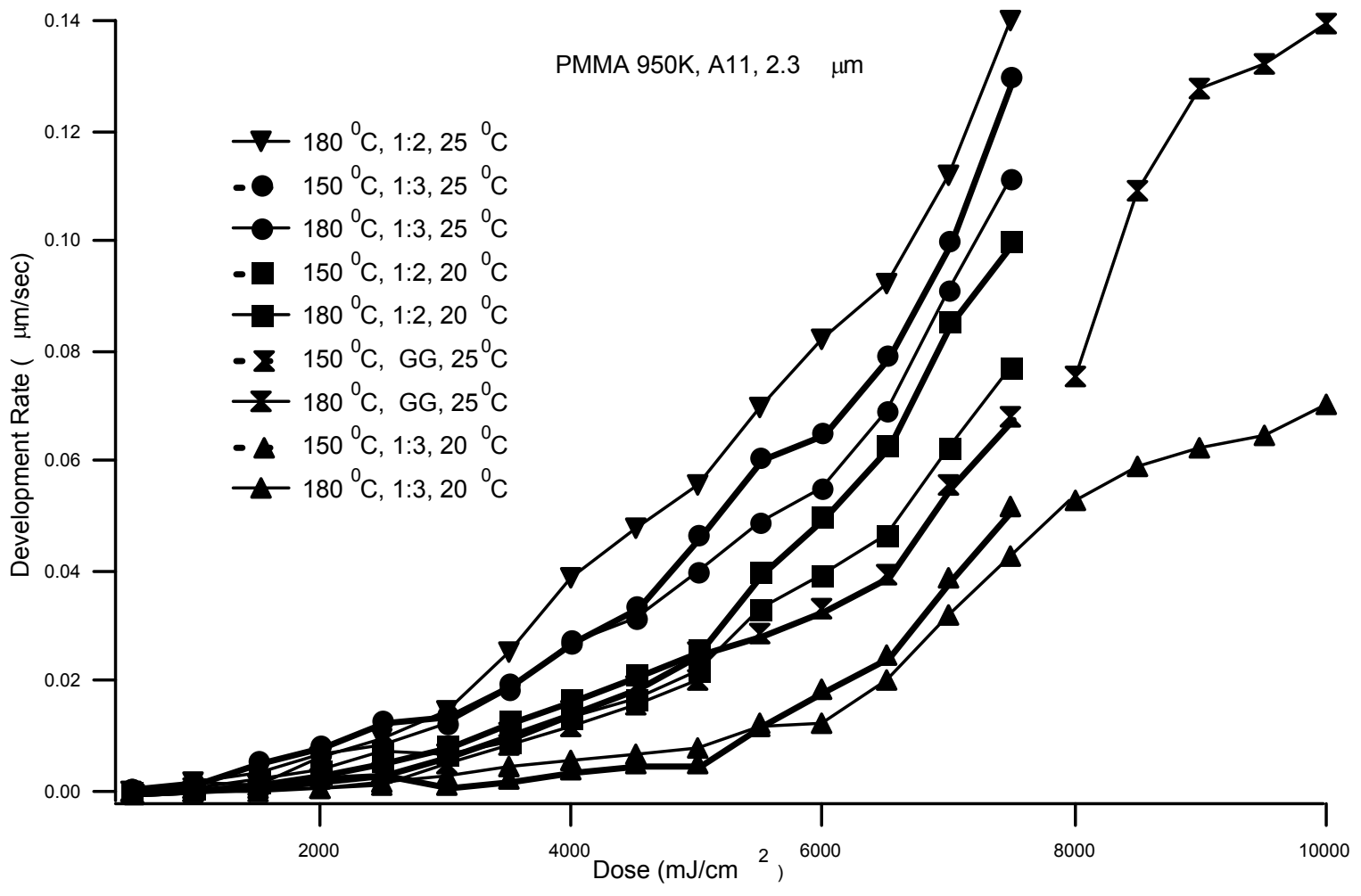

Fig. 2: The development rate for PMMA 950K, A11. 
The development rate is higher for the PMMA treated at $150^{\circ} \mathrm{C}$. During the exposures, the formation of the latent image is accompanied by a loss of material which is higher for the PMMA treated at $150^{\circ} \mathrm{C}$. The observed effect could be associated with migration to the surface and the escape of small volatile molecular fragments produced as a result of the degradation of polymer (radiolysis). ${ }^{20}$ The development rate increases with increasing temperature and changes with the dilution, being smaller for high dilution. The G-G developer system can be used for developing thin layers of PMMA with small or high molecular weight.

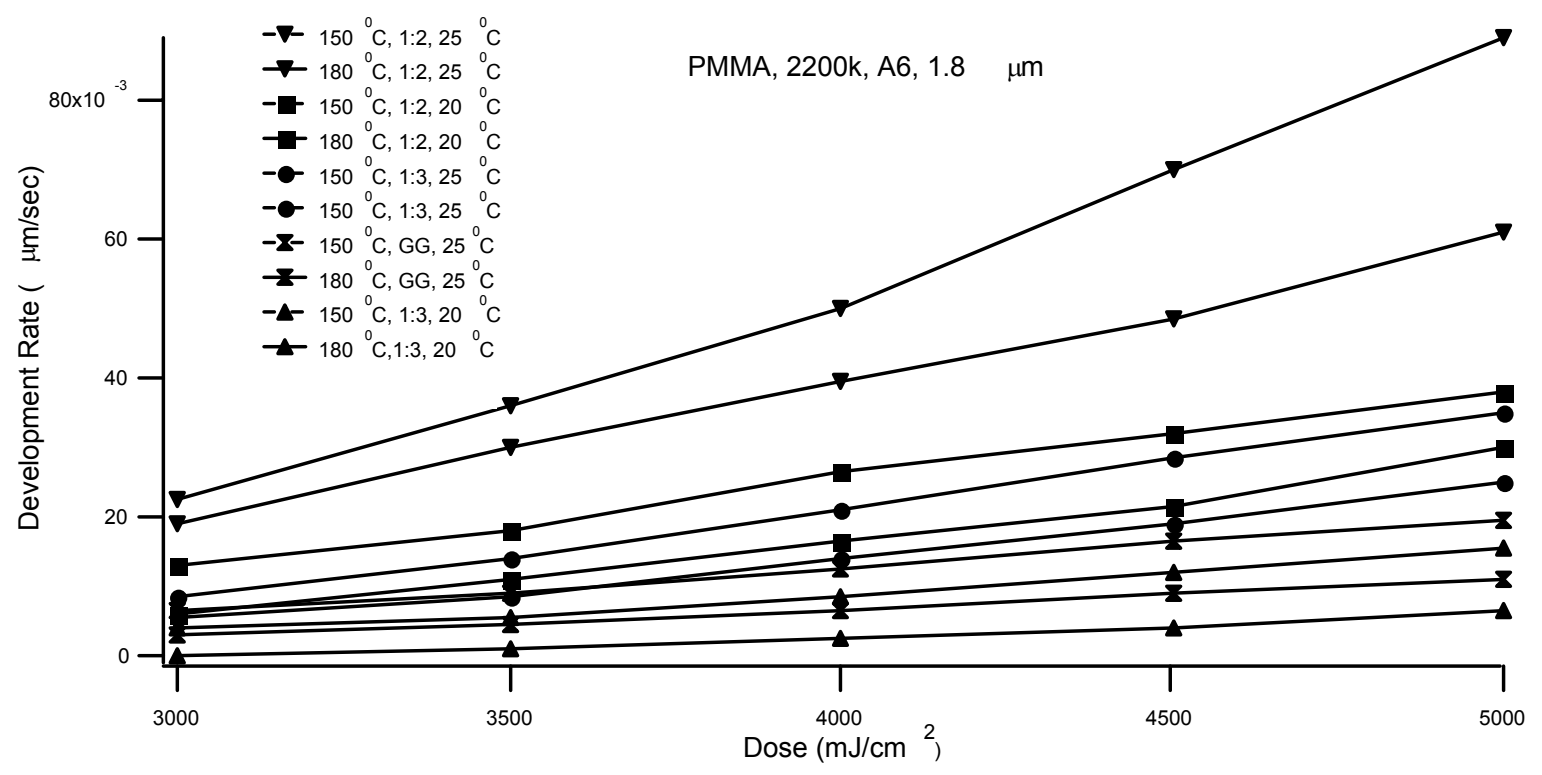

Fig. 3: The development rate for PMMA 2200K, A6.

These data can be used to estimate the dose and the developing parameters for a specific thickness of PMMA. When a x-ray mask is used, it is necessary to consider the differential attenuation produced by the absorber layer and the mask substrate $\left(\mathrm{Si}_{3} \mathrm{~N}_{4}\right.$ membrane). For high-aspect-ratio resist structures we used $1.5 \mu \mathrm{m}$ PMMA, treated at $180^{\circ} \mathrm{C}$, exposed at a dose of $9500 \mathrm{~mJ} / \mathrm{cm}^{2}$, and developed in MIBK:IPA 1:3 at $20^{\circ} \mathrm{C}$ for $1 \mathrm{~min}$.

Since the adhesion of the PMMA film to the as deposited gold substrate is not good enough to pattern 100-150 nm lines, a thin $(30 \mathrm{~nm})$ layer of an organic promoter was used as an intermediate layer between the PMMA and the gold plating base. Usually, this is spin-coated onto the gold plating base. The resist adhesion promoters work by introducing chemisorption forces between the chelating moieties of the promoter layer and the gold surface atoms. ${ }^{21} \mathrm{We}$ compared previous used promoter, diphenyl ethyl triethoxysilane (MS802), and new promoters provided by Gelest Co.: 3mercaptopropyltriethoxysilane (MPTS), 2-(diphenylphosphino)ethyl triethoxysilane (DPTS), 2(diphenylphosphino)ethyl dimethylethoxysilane (DPMS). The Gelest promoters present some advantages: no special annealing step for drying the promoter and no wet etching in diluted hydrofluoric acid (HF) (as for the MS802 promoter) are required. Our best results were obtained with MPTS, which was subsequently used for FZP fabrication on regular basis.

\subsection{Exposure}

The exposures were performed in vacuum. The proximity gap is made by simply clamping together the x-ray mask and the replication sample using a magnet and a $5 \mu \mathrm{m}$-aluminum foil spacer. The first fabricated FZPs had an outermost zone width of $150 \mathrm{~nm}$ or $175 \mathrm{~nm}$ for $0.7 \mu \mathrm{m}$ or $1 \mu \mathrm{m}$ thickness of PMMA, respectively (Fig. 4). 

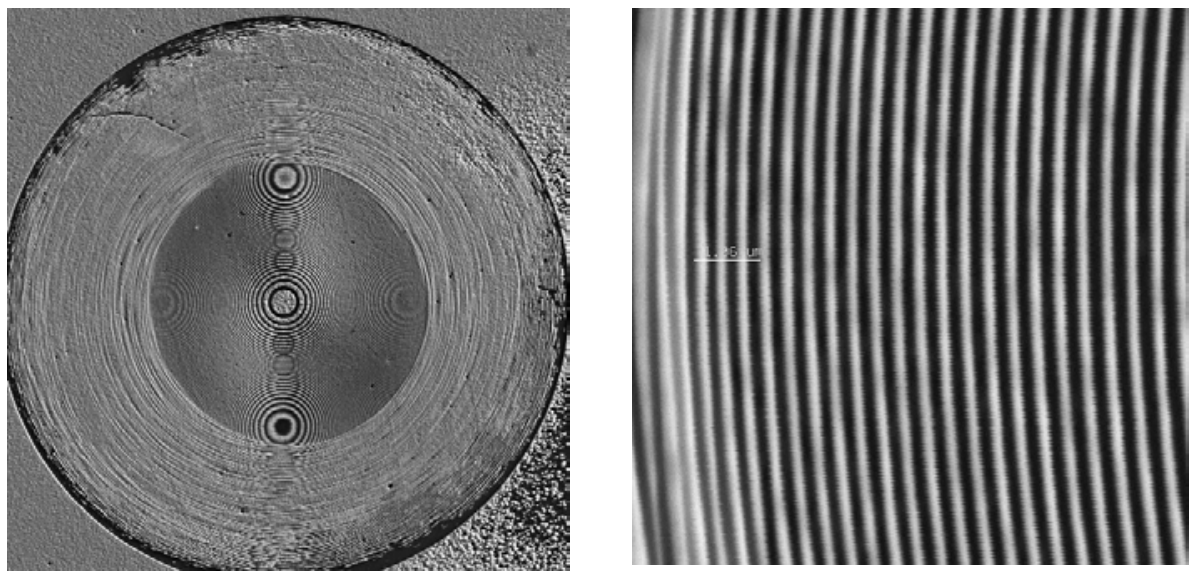

Fig. 4: SEM images of the hard x-ray zone plate with the $175 \mathrm{~nm}$ outermost zone.

The appearance of the collapsed structures (as investigated by SEM) suggests a possible cause of failure due to mechanical displacement between the mask and the exposed PMMA during the exposure step itself (Fig. 5).
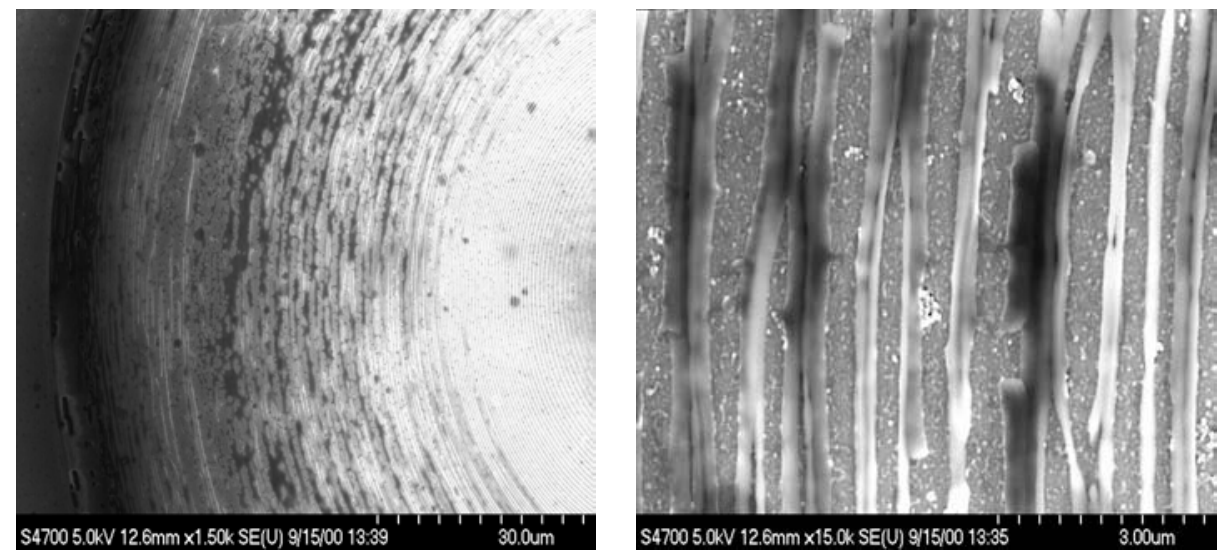

Fig. 5: SEM micrograph of failure in the outermost zone due to mechanical displacement between the mask and the exposed PMMA.

Mechanical displacement can be produced by thermal expansion of the mask/substrate, expansion of the substrate (PMMA film on a $\mathrm{Si}_{3} \mathrm{~N}_{4}$ membrane) due to stress accumulation in the PMMA film, or by vibrations induced by the movement of the scanner. To reduce the displacement possibility, we took the following countermeasures:

- $\quad$ introduced a controlled pressure He atmosphere (500 mTorr) in the scanner chamber, to enhance cooling and damp the membrane vibrations;

- $\quad$ reduced the vibration of the membranes by optimizing the scanning length and scanning speed. 
During these experiments we observed that the exposure was not uniform due to spatial variations in the x-ray beam intensity. The nonuniformity of the exposure causes the nonuniformity of development (Fig. 6) leading to different extent of development for FZP structures even on the same membrane. Thickness variations up to $70 \mathrm{~nm}$ across the $5 \times 5 \mathrm{~mm}^{2}$ membrane area could be observed. These variations in the remaining PMMA thickness also drastically increased the error of estimating the sample area for the electroforming step.

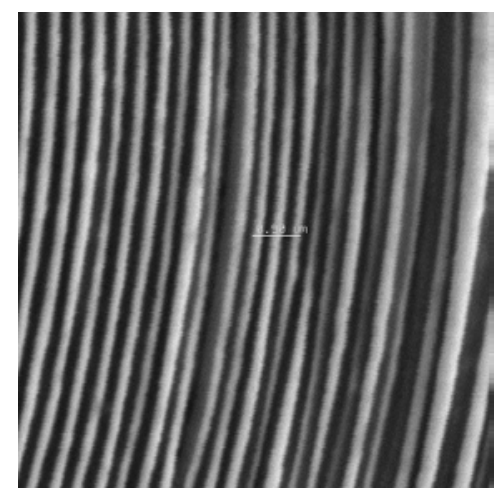

The outermost zone $=180 \mathrm{~nm}$

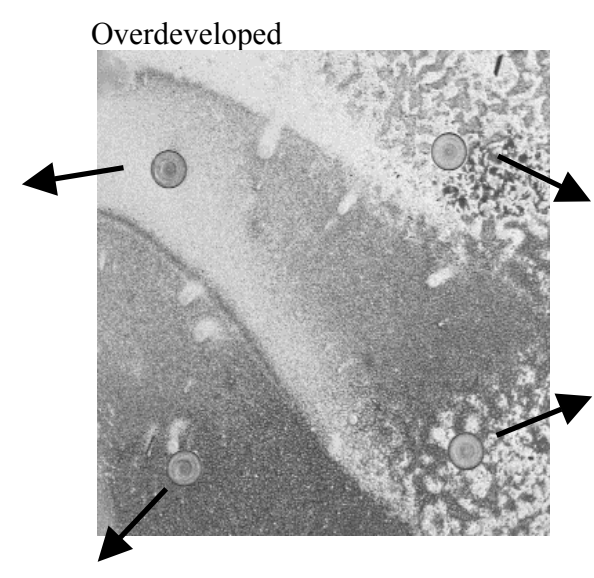

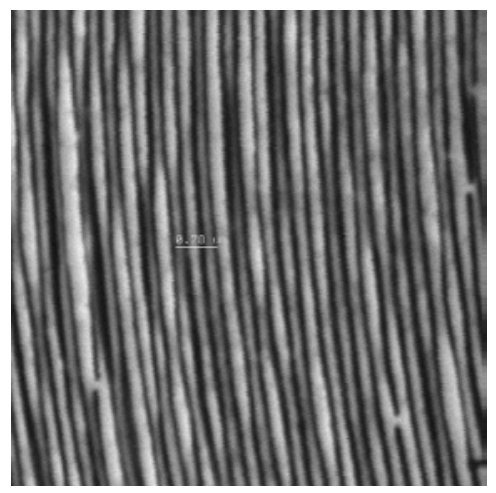

The outermost zone $=130 \mathrm{~nm}$

Fig. 6: The thickness variation of exposed PMMA after the developing step resulting in different outermost zone resolution.

To compensate for the x-ray beam inhomogeneity, we combined the normal vertical scan with a slight displacement in the horizontal, providing a uniform average exposure for the whole sample area.

\subsection{Gold electroforming}

Electroforming gold microstructures is another critical step in the fabrication of high aspect ratio FZP. We experimented two electrolites: Techni-gold 25E (Technic Inc.) and Neutronex 309 (Enthone-OMI Inc.). Gold sulfite $\left[\mathrm{Au}\left(\mathrm{SO}_{3}\right)_{2}\right] \mathrm{Na}_{3}$ is the active ingredient in both solutions. The two solutions operate at neutral or mildly acid $\mathrm{pH}$, respectively. The solutions contain sodium sulfite, ethylenediamine tetraacetic acid (EDTA) as conducting salt, and a stabilizer. The deposited gold obtained with Techni-gold 25E is denser and was chosen to fabricate the FZP structures. This solution can be used also with additives to provide mirror-bright soft or mirror-bright hard deposits having excellent wear resistance. To achieve proper efficiency, uniformity and conformity of the electroforming process, must be determined periodically, and kept constant the gold, sodium sulfite, EDTA, and stabilizer content of the bath. From atomic force microscopy (AFM) measurements, a roughness of $11.88 \mathrm{~nm}(\mathrm{rms})$ was established to be typical for a $1-\mu \mathrm{m}$-thick gold layer obtained with this solution.

Electroforming gold microstructures of the desired thickness $(0.6-1 \mu \mathrm{m})$ is an extremely sensitive process, susceptible to problems originating from poor quality of some plating base coatings, bath contamination, and incorrect operating parameters. Thermostating, magnet stirring, and continuous filtration during the deposition were used to control the deposition rate. In the case of $\mathrm{Ti}-\mathrm{Au}(5 / 25 \mathrm{~nm})$ plating base coatings, we observed random defects in the gold electroplating film, which caused failure of the structures (Fig. 7). The effect was that the gold electroplating started only in some few nucleation spots. The fault was indistinguishable from sample underdevelopment, but plating substrates with no PMMA previously deposited, showed the same behavior. The problem was eliminated by using coatings of $\mathrm{Cr} / \mathrm{Au}(5 \mathrm{~nm} / 30 \mathrm{~nm})$ and by using only high-quality substrates. The failure might be due to the diffusion of titanium through the thin gold film, up to the top of the plating base. 


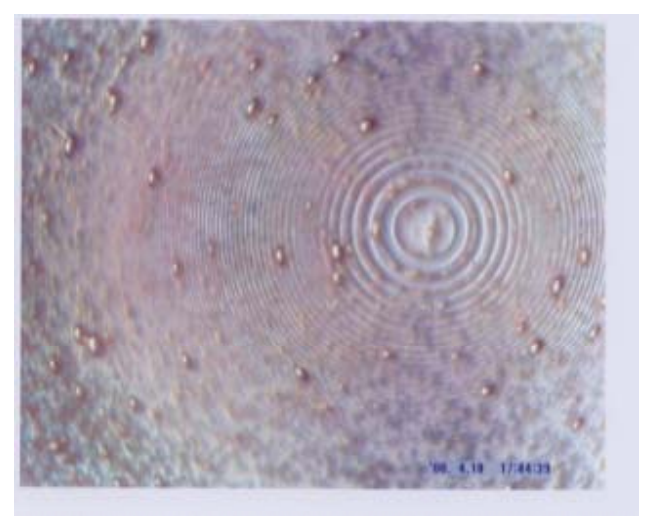

Fig. 7: Defects in a gold electroplating film on a Ti-Au plating base coating.

\section{RESULTS AND DISCUSSION}

In order to improve the resolution and the aspect ratio for hard x-ray zone plates, we established an optimized fabrication process summarized in Table 1, which takes into account all the previously described results.

Table 1. Zone plate processing parameters

\begin{tabular}{|l|c|}
\hline Plate coating base & $\mathrm{Cr} / \mathrm{Au}(5 / 30 \mathrm{~nm})$ \\
\hline Adhesion promoter & MPTS \\
\hline Spin speed & $2500 \mathrm{rpm}$ \\
\hline Resist & $1500 \mathrm{rpm}$ \\
\hline Spin Speed & $180^{\circ} \mathrm{C}$ \\
\hline Soft bake temp. & $1 \mathrm{~h}$ \\
\hline Soft bake time & $2 \mathrm{~h}$ \\
\hline Annealing time & $1.5 \mu \mathrm{m}$ \\
\hline Resist thickness & ES-1 \\
\hline Exposure station & $9500 \mathrm{~mJ} / \mathrm{cm}^{2}$ \\
\hline Exposure dose & $5 \mu \mathrm{m}$ \\
\hline Exposure gap & $25 \mathrm{~mm}$ \\
\hline Y scanning length & Max Scan Dose $500 \mathrm{~mJ} / \mathrm{cm}^{3}$ \\
\hline Scanning speed & $500 \mathrm{mTorr}$ \\
\hline He pressure & $5 \times 1 \mathrm{~mm}$ \\
\hline X scanning length & MIBK:IPA $=1: 3$ at $20^{\circ} \mathrm{C}$ \\
\hline Developer & $1 \mathrm{~min}$. \\
\hline Development time & HF: $\mathrm{H}_{2} \mathrm{O}=1: 30$ for $1 \mathrm{~min}$. \\
\hline Rinsing solution & DIW $1 \mathrm{~min}$. \\
\hline Activation of Au surface & Techni-gold $25 \mathrm{E}, 40^{\circ} \mathrm{C}, 1 \mathrm{~mA} / \mathrm{cm}^{2}$ \\
\hline Rinsing & Continuous filtering, magnetic stirring \\
\hline Electroplating & DIW \\
\hline Rinsing & acetone \\
\hline PMMA removal & \\
\hline
\end{tabular}


Using the fabrication sequence described, we successfully fabricate circular FZPs with $150 \mu \mathrm{m}$ diameter and $110 \mathrm{~nm}$ width of the outermost zone (Fig. 8 (a) and (b)). The remaining defects were proven to be due to defects on the mask (Fig. 8(c)).

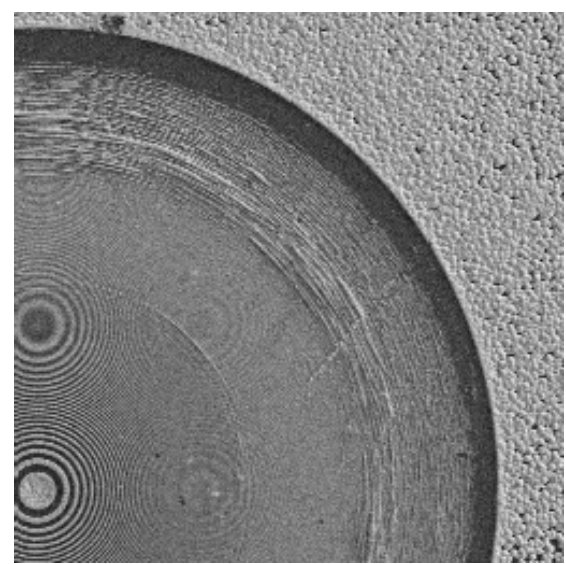

(a)

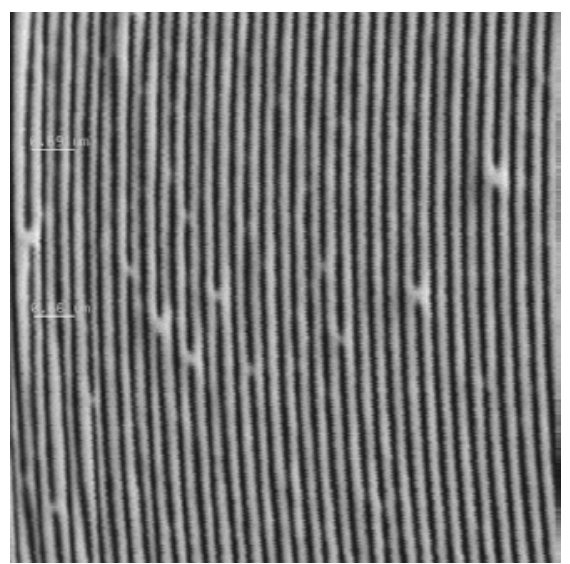

(b)

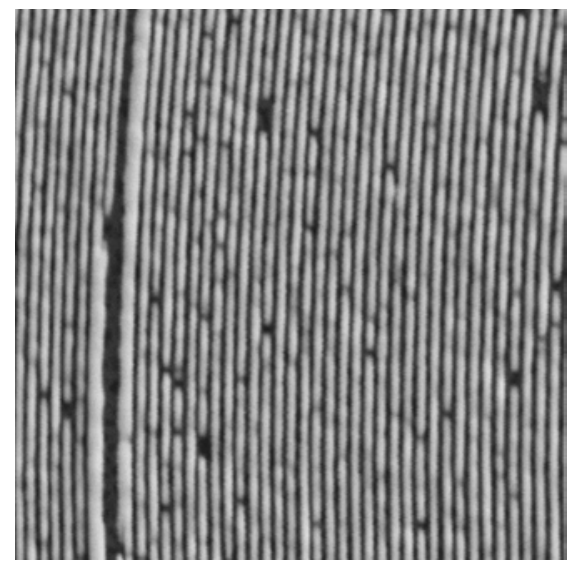

(c)

Fig. 8: SEM images of the hard x-ray zone plate with the $110 \mathrm{~nm}$ outermost zone. (a) center of the zone plate. (b) $110 \mathrm{~nm}$ wide outermost zone. (c) $100 \mathrm{~nm}$ wide outermost zone on the $\mathrm{x}$-ray mask.

The AFM measurements confirmed that the Au thickness is $1.3 \mu \mathrm{m}$, so that an aspect ratio of 11 was achieved using PMMA 950k. For PMMA 2200k, the outermost zone was only $150 \mathrm{~nm}$. Efforts are underway to improve the performances for this resist, to achieve even higher aspect ratios.

The FZP were characterized in terms of diffraction efficiency and focusing spot size. The measurements were performed at $8 \mathrm{keV}$ photon energy at the 2-ID-D beam line of the APS at Argonne National Laboratory. If the inner area of 100 micron diameter of the zone plate was used, we measured a focusing efficiency of $23 \%$. This is in good agreement with the theoretical efficiency of $28 \%$ (assuming 1.3 micron of Au thickness with a bulk density of 19.3), indicating the inner zones are well structured with close to 1:1 filling ratio between the Au and open areas. If the entire zone plate was used, i.e., up to 150 micron diameter, the average efficiency was reduced to $18 \%$, indicating some irregularities of the outer zones. 
The focal spot size was measured using a 20-nm-thick Cr knife-edge mounted on a silicon wafer. The Cr K-alpha fluorescence was monitored while the knife-edge was scanned across the focal spot with $50 \mathrm{~nm}$ steps. By fitting the profile with an Error function (integrated Gaussian), we obtained a spot size of $150 \mathrm{~nm}$ FWHM. This agrees very well with the theoretical resolution of $130 \mathrm{~nm}$ (1.2 times the outermost zone width), and the difference can be accounted for by the reduced contribution to the flux from the outermost zones.

\section{CONCLUSIONS}

Soft x-ray lithography technology has been applied to fabrication of phase shifting FZP's for hard x-rays. Effects of the exposure conditions, developing system, and electroplating process parameters on line width and aspect ratio have been analyzed. The process has been optimized and an aspect ratio of 11 has been achieved for $110 \mathrm{~nm}$ outermost zone width. SEM and AFM have been used for preliminary metrology of the FZPs. The FZP optical performance was characterized at $8 \mathrm{keV}$ photon energy at the 2-ID-D beam line at the Advanced Photon Source. Focusing efficiencies of $23 \%$ for FZPs apertures to 100 microns and $18 \%$ for 150 -micron-diameter apertures have been obtained. The parameters of the fabricated FZP are in good agreement with the predicted values.

\section{ACKNOWLEDGMENTS}

The authors would like to adnowledge Dr. P. Ilinski for his useful discussion and encouragement and Scott Dhuey for SEM measurements. Many thanks go to the technical staff of the APS and SRC clean room facilities for providing excellent working conditions. This work is supported by the U.S. Department of Energy, Office of Science, under Contract No. W31-109-ENG-38. The soft x-ray lithography was conducted at the Synchrotron Radiation Center, University of WisconsinMadison, which is supported by the NSF under Award No. DMR-0084402.

\section{REFERENCES}

1. B. Lai, W. Yun, D. Legnini, Y. Xiao, J. Chrzas, P. Viccaro, V. White, S. Bajikar, D. Denton, F. Cerrina, E. DiFabrizio, M. Gentili, L. Grella, and M. Baciocchi, "Hard x-ray phase zone plate fabricated by lithographic techniques," Appl. Phys. Lett. 61, pp. 1877-1879, 1992.

2. S. J. Spector, C. J. Jaconsen, and D. M. Tenant, "Process optimization for production of sub-20 nm soft x-ray zone plates," J. Vac. Sci. Technol. B 15, pp. 2872-2876, 1997.

3. C. David, B. Kaulich, R. Medenwaldt, M. Hettwer, N. Fay, M. Diehl, J. Thieme, and G. Schmahl, "Low-distortion electron-beam lithography for fabrication of high-resolution germanium and tantalum zone plates," J. Vac. Sci. Technol. B 13, pp. 2762-2766, 1995.

4. E. H. Anderson, V. Boegli, and L. P. Muray, "Electron beam lithography digital pattern generator and electronics for generalized curvilinear structures", J. Vac. Sci. Technol. B 13, pp. 2529-2534, 1995.

5. B. Nieman, D. Rudolph, G. Schmahl, "Soft x-ray imaging zone plates with large zone numbers for microscopic and spectroscopic applications," Optics Communications 12(2), pp. 160-163, 1974.

6. E. H. Anderson, D. L. Olynick, B. Harteneck, E. Veklerov, G. Denbeaux, W. Chao, A. Lucero, L. Johnson, and D. Attwood, "Nanofabrication and diffractive optics for high-resolution x-ray applications," J. Vac. Sci. Technol. B 18 (6), pp. 2970-2975, 2000.

7. M. Li, J. Wang, L. Zhuang, and S. Y. Chou, "Fabrication of circular optical structures with a $20 \mathrm{~nm}$ minimum feature size using nanoimprint lithography," Appl. Phys. Lett. 76 (6), pp. 673-675, 2000.

8. M. Peuker, "High-efficiency nickel phase zone plates with $20 \mathrm{~nm}$ minimum outermost zone width," Appl. Phys. Lett. 78 (15), pp. 2208-2210, 2001.

9. C. David, B. Nöhammer, H. Solak, B. Haas, F. Glaus, J. Friso van der Veen, V. Schlott, J. Bongaerts, B. Kaulich, J. Susini, "Diffractive lenses for photon energies ranging from the extreme ultraviolet to hard x-rays," Proc. SPIE Vol. 4499, pp. 85-95, 2001. 
10. W. Yun, B. Lai, Z. Cai, J. Maser, D. Legnini, E. Gluskin, Z. Chen, A. A. Krasnoperova, Y. Vladimirski, F. Cerrina, E. Di Fabrizio, and M. Gentili, "Nanometer focusing of hard x rays by phase zone plates," Rev. Sci. Instrum. 70 (5), pp.2238-2241, 1999.

11. M. Panitz, G. Schneider, M. Peuker, D. Hambach, B. Kaulich, S. Oestereich, J. Susini, and G. Schmahl, "Electroplated gold zone plates as x-ray objectives for photon energies of 2-8 keV," X-Ray Microscopy: Proceedings of the Sixth International Conference, edited by W. Meyer-Ilse, T. Warwick, and D. Atwood (American Institute of Physics, Melville, NY, 2000), p. 676..

12. E. Di Fabrizio, F. Romanato, M. Gentili, "Toward high resolution and high efficiency zone plate for x-ray applications", X-Ray Microscopy: Proceedings of the Sixth International Conference, edited by W. Meyer-Ilse, T. Warwick, and D. Atwood (American Institute of Physics, Melville, NY, 2000), p. 635.

13. C. David, B. Kaulich, R. Barrett, M. Salomé, and J. Susini, "High-resolution lenses for sub-100 nm x-ray fluorescence microscopy," Appl. Phys. Lett. 77 (23), pp. 3851-3853, 2000.

14. J. Kirz, "Phase zone plates for x rays and the extreme uv," J. Opt. Soc. Am., 64(3), pp. 301-309, 1974.

15. T. Tanaka, M. Morigami, H. Oizumi, T. Ogawa, and S.Uchino, "Prevention of Resist Pattern Collapse by Flood Exposure during Rinse Process," Jpn.J.Appl.Phys. 33, pp. L1803-L1805, 1994.

16. H. Oizumi, Y. Yamashita, T. Ogawa, T. Soga, and R. Yamanaka, "X-ray lithography with a wet-silylated and drydeveloped resist," Jpn.J.Appl.Phys. 35, pp. 6734-6737, 1995.

17. Z. Chen, Y. Vladimirski, F. Cerrina, B. Lai, W. Yun, and E. Gluskin, "0.1 $\mu \mathrm{m}$ High Aspect Ratio Pattern Replication and Linewidth Control," Proc. SPIE Vol. 3331, pp. 591-600, 1998.

18. G. M. Wells, B. Lai, D. So, R. Redaelli, and F. Cerrina, "X-ray lithography beamlines at Aladdin," Nucl. Instrum. Methods A 266, pp. 278-286, 1988.

19. V. Ghica, and W. Glashauser, German Patent No. 3039110, 1982; "Method of stress-free development of irradiated polymethylmetacrylate," U.S. Patent No. 4393129, 1983.

20. Y. Vladimirisky, O. Vladimirisky, K.J. Morris, J. M. Klopf, G. M. Calderon, V. Saile, "PMMA as an x-ray resist for micro-machining application: latent image formation and thickness losses," Microelectronic Engineering 30, pp. 543-546, 1996.

21. J. N. Helbert, "Process for improving adhesion of resist to gold," U.S. Patent No. 4,497,890, 1985. 